\title{
COVID-19: entre a ciência da natureza e a ciência do "espírito"
}

\author{
COVID-19: between science of nature and science of "spirit"
}

\section{Thiago Barros Gomes*}

Resumo: O objetivo do artigo é analisar a interpretação de John Dewey da história da filosofia e de seus problemas para tentar lançar luz sobre o estado de coisas atual, no qual, em meio a uma pandemia de COVID-19, políticos, religiosos e filósofos se confrontam com cientistas numa disputa para determinar quem tem autoridade para determinar como havemos de viver. A distinção que Dewey vê na história da filosofia entre ciências naturais e ciências do "espírito" na modernidade pode indicar a origem desse mal-estar e a resistência da classe "espiritual" em aceitar as orientações da classe dos cientistas.

Palavras-chave: Dewey; Moralidade; Ciência; História da Filosofia; Pandemia; COVID-19

Abstract: I aim to analyze John Dewey's interpretation of the history of philosophy and its problems in an attempt to shed light on the current state of affairs, in which, in the midst of a COVID-19 pandemic, politicians, religious and philosophers confront scientists in a dispute to determine who has the authority to determine how we should live. The distinction that Dewey draws between natural sciences and "spirit" sciences may indicate the origin of this malaise and the resistance of the "spiritual" class to accept the orientations of the class of scientists.

Keywords: Dewey; Morality; Science; History of Philosophy; Pandemic; COVID-19

Jean Hyppolite pensava a Fenomenologia do Espírito como um Bildungsroman ${ }^{1}$, um romance de formação. Nesse gênero literário, o núcleo da história está no processo de desenvolvimento da personagem: a passagem da infância das emoções, das percepções estéticas ou de uma visão de mundo ingênua para a maturidade. A narrativa de um romance de formação percorre sistematicamente por todos os estágios dessa transformação, até a personagem superar a si mesma, que é o telos da história. Hyppolite via na obra de Hegel esta mesma estrutura: "a Fenomenologia é o itinerário da alma que se eleva ao espírito pelo intermédio da consciência ${ }^{2}$; e continua: "A Fenomenologia é (..) o romance de formação filosófica: segue o desenvolvimento da consciência que, renunciando às suas convicções primeiras, atinge através de suas experiências o ponto de vista propriamente filosófico, aquele do saber absoluto"3. Se a intepretação de Hyppolite estiver correta, a personagem de Fenomenologia é a consciência e a obra narra os infortúnios e superações da consciência para realizar a si mesma, quando se identifica com a Razão. Como Cristo, que no fim da história se junta da Deus e se tornam uno.

Michael Baddow argumenta que o Bildungsroman, enquanto gênero moderno europeu, conta a história do desenvolvimento interno da personagem principal e ao fazer isso revela algo da própria natureza humana ${ }^{4}$. No caso de Hegel, revelaria a natureza racional do ser humano e sua necessidade interna de ir ao encontro da Razão, da Verdade.

\footnotetext{
${ }^{1}$ HYPPOLITE, J. Gênese e Estrutura da Fenomenologia do Espírito de Hegel. Tradução de Andrei José Vaczi et al. São Paulo: Discurso Editorial, 1999

${ }^{2}$ Idem, p. 27.

${ }^{3}$ Idem, p. 27.

${ }^{4}$ BEDDOW, M. The Fiction of Humanity: studies in the Bildungsroman form Wieland to Thomas Mann. Cambridge: Cambridge University Press, 1982, p. 5.
} 
Walter Kauffmann, por sua vez, fez outra alegoria literária em sua interpretação da Fenomenologia do Espírito ${ }^{5}$. Ele compreendia a Fenomenologia como uma Divina Comédia ou como um tipo de Fausto. Como Dante, Hegel narra uma "jornada a partir da escuridão e do engano em direção à luz do espírito absoluto" ", a verdade absoluta. O próprio Hegel teria confessado a seu aluno Michelet que a Fenomenologia era sua viagem de descoberta ${ }^{7}$.

As alegorias literárias servem para nos mostrar, de certa forma, como os filósofos veem a si mesmos: heróis de uma epopeia que narra a sucessão de pensamentos extraordinários. Elas figuram aquilo que os filósofos entendem por filosofia e por sua tarefa, isto é, chegar à Verdade e conduzir os seres humanos até lá. Não se trata de uma alegoria tipicamente moderna ou adequada ao idealismo. Interpretações semelhantes poderiam ser feitas com a saída da caverna platônica e os percursos e estágios até as Ideias ou mesmo com as Meditações de Descartes. As referências de claro e escuro para representar o percurso filosófico a ser seguido e os obstáculos a serem enfrentados para se chegar à Verdade são quase ubíquas na história da filosofia.

Essas alegorias, que podem ser vistas quase como parábolas da Razão, dizem bastante sobre o caráter moral implícito à própria atividade do filósofo: resgatar a humanidade da obscuridade irracional e levá-la ao reino da Razão e Iluminação.

John Dewey tinha uma visão pouco apoteótica da origem e da tarefa da filosofia. Ela seria muito menos grandiosa em origem e sua tarefa seria bem menos pretenciosa. De fato, a interpretação de Dewey da história da filosofia e de seus problemas pode ajudar a compreender parcialmente o estado de coisas atual, no qual, em meio a uma pandemia de COVID-19, políticos, religiosos e filósofos se confrontam com cientistas numa disputa para determinar quem tem autoridade para determinar como havemos de viver. A distinção que Dewey vê na história da filosofia entre ciências naturais e ciências do "espírito" pode indicar a origem desse mal-estar e a resistência da classe "espiritual" em aceitar as orientações da classe dos cientistas.

Dewey tenta oferecer uma genealogia naturalizada do pensamento. Ele teria origem naquilo que diferenciaria os seres humanos dos animais: a capacidade de reter experiência, ou seja, a memória. O ser humano é capaz de utilizar as experiências passadas no presente e o faz através de sinais e símbolos. Como Dewey afirma: "O homem não vive, portanto, como os animais das selvas ou dos campos, num ambiente de coisas meramente físicas, mas sim num mundo de sinais e símbolos"8. Nesse sentido, Dewey parece igualar humanidade, cultura e capacidade de criar símbolos e sinais. Talvez possamos dizer que, para ele, a cultura é o mundo de sinais e símbolos.

Ao vivenciar as experiências na memória, ou quando as contamos para outros seres humanos, "reconstituímos imaginativamente"9 essas experiências. Damos a elas uma estrutura que antes, quando vividas, não tinham. Quando as revivemos "surge um drama com início, um meio e um movimento em direção ao clímax da vitória ou do fracasso". Em outras palavras, nossa memória, isto é, nossa forma própria de moldar as experiências passadas para atuarem no presente, possui uma estrutura narrativa.

A aceitação dos símbolos e das narrativas não seria plenamente inteligente, mas visaria satisfazer necessidades emocionais. Com a aceitação, comenta Dewey, forma-se uma tradição: "O corpo de crenças ditados pelo desejo e pela imaginação, e transformado em tradição oficial por influência da autoridade comunal, tudo penetrava e abrangia, fazendo-se, por assim dizer, onipresente em todas as minudencias da vida grupal"10.

Nesse sentido, quando a filosofia surgiu na Grécia, ela se desenvolveu num contexto de uma tradição estabelecida. Era uma sociedade politeísta, escravocrata e com uma estrutura valorativa e

\footnotetext{
${ }^{5}$ KAUFMANN, W. Hegel: a reinterpretation. Notre Dame: University of Notre Dame Press, 1978, p. 115.

${ }^{6}$ CORNGOLD, S. Walter Kaufmann: Philosopher, Humanist, Heretic. Princeton: Princeton University Press, 2019, p. 248

${ }^{7}$ MENESES, P. Hegel e a Fenomenologia do Espirito. Rio de Janeiro: Zahar, 2003

${ }^{8}$ DEWEY, J. Reconstrução em Filosofia. Tradução de António Pinto de Carvalho. São Paulo: Companhia Editora Nacional, 1959, p. 44.

${ }^{9}$ Idem p. 45.

${ }^{10}$ Idem, p. 46.
} 
de posição social já bem definida. A nobreza ateniense se dedicava às expressões superiores da alma: as coisas públicas, a poesia, e, posteriormente, a filosofia. Os artífices e os escravos se dedicavam a atividades menos nobres, aquelas que envolviam o corpo e a atividade manual. A nobreza se dedicava ao conhecimento abstrato das questões morais, políticas e espirituais; em razão disso, eram atribuídas a ela a autoridade sobre tais assuntos. Os artífices e os trabalhadores manuais se dedicavam a um conhecimento positivo, transmitido ou aprendido experimentalmente. Mas diante de questões morais ou políticas, eles deveriam seguir as orientações daquela outra classe.

O interesse dos filósofos não seria romper com essa tradição, mas antes ocupar o lugar de autoridade do poeta, do político ou do sacerdote. Dewey argumenta que o grande projeto platônico é assentar a tradição, isto é, justificar a autoridade e moralidade, não mais em termos de costumes tradicionais, mas preservar a autoridade se valendo de uma justificativa racional. Trata-se de uma purificação dos costumes, mais do que uma mudança drástica. Desse modo, era interesse de Platão:

Desenvolver um método de pesquisa e de prova racional, que assentasse em base sólida os elementos essenciais das crenças tradicionais: desenvolver um método de pensar e de conhecer que a um tempo purificasse a tradição e lhe preservasse, inalterados, os valores morais e sociais; mais ainda, que, purificando-os, lhes incrementasse o poder e autoridade. Numa palavra, deveria ser restabelecido aquilo que se baseava no costume, de sorte que seu fundamento não mais fossem os hábitos do passado, mas a genuína metafísica do Ser e do Universo ${ }^{11}$.

Dewey enxerga no conhecimento do artífice, o que ele chama de conhecimento positivo, o embrião daquilo que se tornaria a ciência moderna. Ele seria um tipo de conhecimento cujo valor prático é inegável, mas que não conta com o mesmo tipo de prestígio atribuído pelas autoridades sociais - o político, o sacerdote e o filósofo - aos conhecimentos em matéria de moral, religiosa e política, ou seja, em termos de valores e ideais. Dessa forma, o artífice nunca teria o direito de participar da pesquisa racional acerca dos valores e ideais. Segundo Dewey:

Tanto o destino de Sócrates como a má reputação dos sofistas dão ensejo a mostrar alguns contrastes marcantes entre crenças tradicionais, baseadas no sentimento, de um lado, e conhecimento reais, prosaicos, positivos, de outro lado: o objetivo da comparação será o de focalizar o fato de que, embora todas as vantagens oriundas do que hoje denominamos ciência estivessem do lado do conhecimento positivo, os proveitos da estima e da autoridade social, bem como os benefícios do contato íntimo com tudo aquilo que confere à vida seus valores mais profundos, se encontravam do lado das crenças tradicionais. Segundo todas as aparências, o conhecimento específico e verificado do meio tinha apenas alcance limitado e técnico. Referia-se somente às artes e o objetivo e o bem do artífice não ia por certo muito longe, sendo subordinados e quase servis. Quem situaria a arte do sapateiro em plano igual ao da arte de governar o Estado? Quem elevaria mesmo a arte mais nobre do médico, que cura o corpo, ao nível de arte do sacerdote que cura a alma? Por esta forma é que Platão analisa constantemente, em seus diálogos, os respectivos contrastes. O sapateiro julga de boa ou má qualidade dos sapatos, mas não é juiz na questão mais importante de saber se e quando há conveniência de usar sapatos; o médico é bom julgador em matéria de saúde, mas quanto a saber se é preferível gozar da boa saúde ou morrer, não o sabe ${ }^{12}$.

Com o surgimento da ciência experimental moderna e o sucesso das ciências naturais, a posição dos filósofos e religiosos como guias morais da humanidade foi colocada em risco. Se o método experimental era tão bem-sucedido, por que não o aplicar aos problemas da moral e da política? Haveria o receio de que se o ser humano moderno aceitasse plenamente o método experimental, isso implicaria numa revisão de crenças em ideias e conceitos fixos e eternos, que fundamentariam o comportamento e as instituições humanas. Em outras palavras, se aceitássemos

\footnotetext{
${ }^{11}$ Idem, pp. 55-56.
}

${ }^{12}$ Idem, pp. 53-54. 
certa explicação científica da realidade, essa explicação necessariamente implicaria em revisões sucessivas de outras áreas da realidade, não apenas das ciências naturais. Consequentemente, provocaria uma mudança nas nossas concepções políticas, religiosas, sociais e morais.

Os filósofos modernos teriam sido bastante astutos diante do desafio de lidar com a visão científica nascente e suas visões filosóficas, ainda presas à busca de um fim último. A solução encontrada foi traçar uma separação entre os domínios da ciência natural e o domínio das ciências do "espírito". Nesse último domínio se encontraria a ética ou moral e todos os campos de investigação que seriam diretamente afetados pelos avanços da ciência moderna. A separação também se refletiria no tipo de método próprio a cada domínio: no das ciências naturais, o método experimental de observação, criação de hipóteses e experimentação; no das ciências do "espírito", a filosofia como estava sendo feita desde a antiguidade, isto é, a busca por princípios fixos e eternos.

Essa distinção, entretanto, não seria apenas uma separação de áreas de investigação ou de metodologia, ela teria uma função política por detrás. A separação entre ciências naturais e ciências do "espírito" preservaria os loci de autoridade, tanto do religioso e do político quanto do filósofo, enquanto guias morais que se viam ameaçados pelos resultados da ciência natural. Como resultado, as ciências naturais teriam seu objeto e método de estudo próprios e diferentes daqueles da ciência do "espírito".

Hoje ainda podemos ver a disputa entre as ciências naturais e as ciências do "espírito", que Dewey tinha identificado na modernidade, bem como o loci de autoridade moral atribuído ao último. Com a pandemia, talvez essa disputa tenha ficado ainda mais clara, pois o que está em jogo pode ser entendido como uma questão de quem tem a autoridade de dizer como havemos de viver.

Antes da pandemia, uma pessoa diante de tal questão tentaria encontrá-la na fé religiosa sua reposta; poderia também confiar nas diretrizes políticas do Estado, segui-las inconscientemente ou então recorreria a algum filósofo político ou eticista. Ou seja, a resposta seria encontrada dentro daquilo que Dewey chamou de ciência do "espírito". Em meio à pandemia de COVID-19, a resposta à questão de como havemos de viver certamente passaria pelas mãos de um cientista. $\mathrm{E}$ isso traz um grande desconforto para os cientistas do "espírito", que veem suas autoridades ameaçadas.

O desconforto causado pelos cientistas da natureza, ao assumir a autoridade em matéria de moralidade, pode explicar em parte os ataques que a ciência tem sofrido tanto por religiosos quanto por políticos (embora no cenário nacional essas duas personagens muitas vezes ocupam o mesmo papel). Silas Malafaia, líder da igreja Assembleia de Deus, é um exemplo caricatural de negacionista do COVID-19. Ele costuma chamar a quarentena de farsa e negar ora a existência, ora a letalidade do vírus. No dia nove de abril, a Justiça do Rio de Janeiro determinou a proibição de cultos presenciais, seguindo orientações da $\mathrm{OMS}^{13}$ de se evitar aglomerações. A proibição, na prática, determina que Malafaia não é senhor na própria igreja e outorga aos cientistas a autoridade de dizer como ele e os fiéis devem viver. O maior receio de Malafaia para com a ciência, no entanto, talvez se deva ao pensamento de que sua autoridade enquanto guia moral pode acabar. Se os fiéis aceitarem a autoridade dos cientistas em relação a COVID-19, em breve a aceitarão em outras questões, não apenas "científicas", mas sobre as quais o pastor teria autoridade exclusiva.

De forma análoga, a autoridade do presidente Bolsonaro, em sua mescla de autoritarismo militarizado, conservadorismo religioso e êxtase neoliberal, é colocada em dúvida pelas orientações dos cientistas da natureza. A recorrente minimização dos sintomas e das mortes provocados pelo COVID-19, em evidente negação aos fatos, bem como a fúria contra aos governadores estaduais (que até então tentavam seguir as recomendações da OMS) são sinais de receio de sua autoridade solapada pela ciência. A junção do Estado e do capitalismo nega a autoridade da ciência da natureza para determinar o fechamento do comércio, o que serviria para controlar o avanço da pandemia. Afinal, caberiam ao presidente e ao ministro da fazenda determinar os valores sociais e os meios para realiza-los. E se o valor final é o crescimento econômico infindável, as recomendações da OMS são obstáculos para a realização deste ideal.

${ }^{13}$ Organização Mundial da Saúde. 
Giogio Agamben, no artigo, "a invenção da pandemia"14, publicado na coletânea Sopa de Wuhan também minimiza a letalidade do vírus, que, segundo ele, só provoca sintomas leves. Agamben fez sua análise logo no início da pandemia e, por isso, estava sujeito aos riscos inerentes da precipitação. No entanto, sua análise mantém a desautorização e a suspeição dos cientistas em matéria de política e moral. Agamben argumenta que o "falso vírus" legitimaria um "estado de exceção", que suspenderiam as liberdades de ir e vir dos cidadãos. A "falsa epidemia" seria uma arma estatal para incitar o pânico na população. Com o pânico instalado no âmbito da vida comum, os Estados nacionais poderiam implementar sistemas cada vez mais eficientes de vigilância e controle. Embora o isolamento social seja uma orientação OMS para desacelerar a transmissão comunitária do vírus, Agamben não consegue ver boa-fé nas sugestões dos cientistas ou, talvez, suspeitasse da ingenuidade dos cientistas, que, por não entenderem de política ou das ciências do "espírito", seriam manipulados e usados para a realização de um "estado de exceção".

No entanto, a forma de agir descrita por Agamben está correta: os Estados utilizam da pandemia para justificar políticas públicas que encontrariam resistência fora de um estado de exceção. O COVID-19 serviu para os Estados justificarem a seus cidadãos a troca de liberdade por saúde. Esse é o argumento por trás da aceitação do uso de dados de localização de celulares para a identificação de possíveis pessoas contaminadas e serviu tanto para permitir o acesso às informações de cidadãos na China quanto em democracias liberais da Europa.

No Brasil, o COVID-19 permitiu a aceleração das pautas neoliberais, que já estavam em andamento da pandemia. O vírus ora servia como cortina de fumaça para a opinião pública, ora servia como argumento para o afrouxamento de leis e regras para o benefício de grupos empresariais. E essa forma de agir se deu nos âmbitos municipal, estadual e federal.

Podemos citar dois exemplos que não estão em evidência: o setor de transporte e a educação. Antes da pandemia, as empresas de ônibus da Grande Vitória tentavam a todo custo acabar com a função de cobrador. O motorista desempenharia as duas funções (cobrar e conduzir) ou seria obrigatório o uso de bilhete eletrônico próprio da empresa (sem opção de dinheiro em espécie). Essas tentativas sempre foram frustradas pelos trabalhadores, que, diante da ameaça de demissão dos colegas, entravam em greve. Contudo, o governo estadual autorizou a suspensão dessa função em decorrência da pandemia. A vontade dos empresários foi realizada e dificilmente veremos cobradores nos ônibus após a pandemia. Da mesma forma, o governo federal afrouxou as regras e as diretrizes que regulavam o ensino à distância. O COVID-19 serviu de argumento para que o Estado permitisse que as grandes empresas do setor da educação reduzissem o tamanho e a qualificação de seus corpos docentes. Hoje vemos demissões em massa em São Paulo, um professor lecionando para inúmeras turmas virtuais ao mesmo tempo ou cedendo uso de imagem por trinta anos para uma grande rede de ensino. Provavelmente essas ações não serão desfeitas.

O mundo será melhor depois do COVID-19? Não há evidências para corroborar com ideias esperançosas de um novo mundo porvir das ruínas da pandemia, como se depois de uma grande desgraça houvesse uma recompensa igualmente grande para dar sentido ao que foi perdido. $\mathrm{O}$ comunismo, uma sociedade democrática solidária e cooperativa, o fim do neoliberalismo, entre outras ideias esperançosas, são apenas telos de uma história da qual não estamos suficientemente longe para ver. Após a pandemia, certamente teremos um mundo melhor, da mesma forma que após a Segunda Guerra Mundial não existiu um país declaradamente nazista, após a pandemia não haverá um vírus mortal. Mas as coisas que nos espantam hoje, o egoísmo, o populismo, o anticientificismo, isso continuará existindo, da mesma forma que ainda hoje (infelizmente) existem nazistas.

Depois da pandemia, certamente teremos um mundo melhor. Afinal, não haverá um vírus mortal, assim como após a Segunda Guerra Mundial não existiu um país declaradamente nazista. Mas as coisas que nos espantam hoje, o egoísmo, o populismo, o anticientificismo, isso continuará existindo, da mesma forma que ainda hoje (infelizmente) existem nazistas.

Se a nossa interpretação da história da filosofia de Dewey estiver correta, a pandemia borra e anuvia a autoimagem dos filósofos, políticos e religiosos a respeito de seus papeis na orientação e

${ }^{14}$ AGAMBEN, G. La invencion de uma epidemia. In Sopa de Wuhan. ASPO, 2020. 
guia moral dos seres humanos. Eles já não são capazes de, sozinhos, dizer como havemos de viver. A pandemia mostra a necessidade de inserir os cientistas nas discussões morais, sendo a moralidade tomada em seu sentido grego de oferecer uma resposta de como devemos viver, agora em tempos de COVID-19. Os países que tornarem essa tarefa moral como algo cooperativo salvarão mais vidas. Países que estimularem a queda de braço entre ciência naturais e ciências do "espírito", entre cientistas e aqueles que se veem como guias morais - filósofos, políticos e religiosos - perceberão muito tarde seus erros.

\section{Referências}

AGAMBEN, G. La invencíon de uma epidemia. In Sopa de Wuhan. ASPO, 2020.

BEDDOW, M. The Fiction of Humanity: studies in the Bildungsroman form Wieland to Thomas Mann. Cambridge: Cambridge University Press, 1982, p. 5.

CORNGOLD, S. Walter Kaufmann: Philosopher, Humanist, Heretic. Princeton: Princeton University Press, 2019, p.248

DEWEY, J. Reconstrução em Filosofia. Tradução de António Pinto de Carvalho. São Paulo: Companhia Editora Nacional, 1959, p. 44.

HYPPOLITE, J. Gênese e Estrutura da Fenomenologia do Espírito de Hegel. Tradução de Andrei José Vaczi et al. São Paulo: Discurso Editorial, 1999

KAUFMANN, W. Hegel: a reinterpretation. Notre Dame: University of Notre Dame Press, 1978, p. 115.

MENESES, P. Hegel e a Fenomenologia do Espírito. Rio de Janeiro: Zahar, 2003 